\title{
Expression of mRNA coding for four catecholamine- synthesizing enzymes in human adrenal pheochromocytomas
}

Kazumasa Isobe, Toshiaki Nakai, Nobuyasu Yukimasa, Toru Nanmoku, Kazuhiro Takekoshi and Fumio Nomura

Department of Clinical Pathology, Institute of Clinical Medicine, University of Tsukuba, Tsukuba, Ibaraki, 305, Japan

(Correspondence should be addressed to K Isobe, Department of Clinical Pathology, Institute of Clinical Medicine, University of Tsukuba, 1-1-1 Tennoudai, Tsukuba, 305, Japan)

\begin{abstract}
Objective: To understand the molecular mechanisms by which catecholamine synthesis is controlled in pheochromocytomas - tumors that synthesize and release catecholamines, which are related to various clinical manifestations of the condition.

Methods: We measured the concentrations of mRNA coding for the catecholamine-synthesizing enzymes tyrosine hydroxylase, aromatic L-amino acid decarboxylase (AADC), dopamine $\beta$-hydroxylase (DBH) and phenylethanolamine $N$-methyl transferase (PNMT) and for the catecholamine contents in 12 pheochromocytomas and 12 normal adrenal medullas.

Results: The mean content of total catecholamine and the $\beta$-actin mRNA expression in the pheochromocytomas were almost the same as those in the normal adrenal medullas. However, the tyrosine hydroxylase, AADC and DBH mRNA concentrations in the pheochromocytomas were greater than those of the normal adrenal medullas. Conversely, the PNMT mRNA concentration in the pheochromocytomas was lower than that in the normal adrenal medullas. These differences are responsible for the difference in the proportions of catecholamines between pheochromocytomas and normal adrenal medullas. The constitutive expression of the catecholamine-synthesizing enzyme mRNAs varied in magnitude among the pheochromocytomas, and the tyrosine hydroxylase mRNA expressions correlated with the contents of total catecholamine in the tumors $(r=0.964, P<0.0001)$. Conclusions: These findings indicate that catecholamine production in pheochromocytomas is primarily controlled by the level of gene expression.
\end{abstract}

European Journal of Endocrinology 138 383-387

\section{Introduction}

Pheochromocytomas are tumors arising most often from the adrenal medulla. They synthesize, store and release catecholamines (1-3). However, unlike the adrenal medulla (4), pheochromocytomas are not innervated, and the catecholamine release by pheochromocytomas is not initiated by neural impulses. The mechanism of catecholamine release from pheochromocytoma is not yet clear, nor is the regulation of catecholamine synthesis in these tumors.

Tyrosine hydroxylase, the rate-limiting enzyme in the biosynthesis of catecholamines, is distributed in sympathetic ganglia, the adrenal medulla, the central nervous system and also in pheochromocytomas (5). Its activity is modulated by the phosphorylation of the tyrosine hydroxylase molecule (6) and by long-term regulation involving tyrosine hydroxylase gene (TH gene) transcription and protein synthesis (7).

A variety of factors, including neural impulses, have been reported to regulate the $\mathrm{TH}$ gene expression in adrenal medullary cells $(8-10)$. The expression of the TH gene has also been studied in rat pheochromocytoma cell lines (11-13). Compared with the information available concerning $\mathrm{TH}$ gene expression in experimental cell lines, our knowledge about the expression of this gene in human pheochromocytomas is limited (14).

The catecholamines dopa, dopamine, noradrenaline and adrenaline are synthesized enzymatically by four enzymes; tyrosine hydroxylase, aromatic L-amino acid decarboxylase (AADC), dopamine $\beta$-hydroxylase (DBH) and phenylethanolamine $N$-methyl transferase (PNMT) respectively, and the activities of these enzymes are regulated over the long term by the gene expressions of the enzymes.

We report here our data on the expression of mRNAs coding for the catecholamine-synthesizing enzymes tyrosine hydroxylase, AADC, DBH and PNMT, and on the simultaneous measurements of tissue catecholamine concentrations in 12 human adrenal pheochromocytomas and 12 normal human adrenal medullas.

\section{Materials and methods}

\section{Materials}

Isogen for RNA isolation was obtained from Nippon Gene (Tokyo, Japan). Hybridization membranes and a 
random primer DNA labeling kit were purchased from Du Pont (Boston, MA, USA). cDNAs for tyrosine hydroxylase, AADC and DBH were obtained from the Riken DNA Bank (Tsukuba, Japan). cDNAs for PNMT and bovine $\beta$-actin were gifts from Dr T Nagatsu (Fujita Health University, Japan) and Dr Y Kawakami (Tsukuba University, Japan) respectively. ${ }^{32} \mathrm{P}-\mathrm{dCTP}$ was obtained from Amersham (Amersham, Buckinghamshire, UK). Other chemicals were of reagent grade.

\section{Tissue samples}

Tumor specimens were obtained surgically from 12 patients with pheochromocytoma, and 12 normal adrenal glands were obtained at surgery at the time of nephrectomy for renal cell carcinomas. Each specimen was frozen at $-80^{\circ} \mathrm{C}$ until required for assay. The pheochromocytoma specimens were all of adrenal origin.

Two experiments (A and B) were performed for the northern blot analysis, to avoid the degradation of mRNA in the tissues.

\section{Determination of catecholamine contents}

The tissue concentrations of catecholamines (adrenaline, noradrenaline and dopamine) were determined using a catecholamine autoanalyzer (H8030, TOSOH, Tokyo, Japan) with built-in HPLC and a spectrofluorimeter. Fifty milligrams of each specimen were minced in $1 \mathrm{ml}$ extraction buffer $\left(2 \% \mathrm{HClO}_{4}, 1 \mathrm{mM}\right.$ ascorbic acid and $100 \mathrm{mM}$ EDTA). The homogenate was centrifuged at 10000 times gravity for $20 \mathrm{~min}$ at $4{ }^{\circ} \mathrm{C}$. The supernatant was diluted by 1000 and applied to the autoanalyzer.

\section{Isolation of RNA and northern blot analysis}

Total RNAs were extracted from the tissues using the Isogen kit, and the RNA concentrations were estimated spectrophotometrically at $260 \mathrm{~nm}$. RNA (10 $\mu \mathrm{g}$ each) was fractionated by electrophoresis on 1\% agarose- $5 \%$ formaldehyde gels $(80 \mathrm{~V} 2 \mathrm{~h})$. After staining with ethidium bromide and the visual inspection of u.v. fluorescence to confirm the presence of equal amounts of ribosomal RNA in each lane, the RNA was transferred to a nitrocellulose membrane and hybridized to ${ }^{32}$ P-labeled probes.

The following probes were used: $1.9 \mathrm{kbp}$ EcoRI fragment of pTHT1 for tyrosine hydroxylase, a $2 \mathrm{kbp}$ EcoRI and EcoRV fragment of pDBH-1 for DBH, $1.9 \mathrm{kbp}$ EcoRI fragment of pPCDC13EcoA for AADC, and $901 \mathrm{bp}$ SmaI and KpnI fragment of phPNMT for PNMT. Plasmid pTHT1 contained the full-length cDNA for human tyrosine hydroxylase type 1 cDNA. Plasmids pDBH-1, pPCDC13EcoA and phPNMT contain human DBH cDNA, human AADC cDNA and human PNMT cDNA respectively. These plasmids were developed by T Nagatsu (15), K Kobayashi (16), H Ichinose (17) and T Nagatsu (18) respectively. The cDNA probes were labeled by a random primer extension labeling system (New England Nuclear, Boston, MA, USA). The membranes were also hybridized with a ${ }^{32}$ P-labeled bovine $\beta$-actin cDNA probe after stripping. Hybridization signals were scanned in an image analyzer (BAS2000, Fuji, Tokyo, Japan).

\section{Statistical analysis}

All values are expressed as means \pm S.E. Statistical significance was determined by Student's $t$-test and the Mann-Whitney U-test. Correlations between the tissue concentrations of total catecholamine and tyrosine hydroxylase mRNA were determined by Pearson's test. The significance level was set at $P<0.05$.

\section{Results}

The tumor weights and sizes and the tissue, plasma and urine catecholamine concentrations in the 12 adrenal pheochromocytomas are listed in Table 1. We found

Table 1 Tissue, plasma and urine catecholamine concentrations in the 12 adrenal pheochromocytomas.

\begin{tabular}{|c|c|c|c|c|c|c|c|c|c|c|c|}
\hline \multirow[b]{2}{*}{ No. } & \multirow{2}{*}{$\begin{array}{c}\text { Tumor weight } \\
\text { (g) }\end{array}$} & \multirow{2}{*}{$\begin{array}{l}\text { Tumor size } \\
(\mathrm{cm})\end{array}$} & \multicolumn{3}{|c|}{ Tissue CA $(\mathrm{nmol} / \mathrm{g})$} & \multicolumn{3}{|c|}{ Plasma CA (nmol/l) } & \multicolumn{3}{|c|}{ Urine CA (nmol/day) } \\
\hline & & & $A$ & NA & DA & $A$ & NA & DA & $A$ & NA & DA \\
\hline 1 & 58 & $7.5 \times 6.5 \times 2.5$ & 737 & 16430 & 131 & - & - & - & 57 & 3239 & 4506 \\
\hline 2 & 21 & $3.8 \times 3.5 \times 3.0$ & 36036 & 27304 & 327 & 68.00 & 61.90 & 2.24 & 2184 & 1282 & 6442 \\
\hline 3 & - & 5 & 1147 & 2719 & 0 & 1.22 & 2.06 & 0.03 & 187 & 1382 & 14143 \\
\hline 4 & 193 & $8 \times 8 \times 5$ & 27 & 225 & 0 & - & - & - & - & - & - \\
\hline 5 & 110 & $9.5 \times 6.5 \times 4.0$ & 11 & 41 & 0 & 0.11 & 2.54 & 0.07 & 33 & 6572 & 2727 \\
\hline 6 & 44 & $5.5 \times 4.5 \times 3.0$ & 2763 & 14598 & 3898 & - & 7.21 & - & - & 2352 & - \\
\hline 7 & - & 1 & 27 & 3853 & 0 & 0.20 & 5.06 & 0.07 & - & - & - \\
\hline 8 & - & 4 & 0 & 248 & 0 & - & 13.40 & - & - & 2300 & - \\
\hline 9 & - & $4.6 \times 3.7$ & 142 & 5331 & 137 & 0.46 & 70.30 & 3.96 & - & $\begin{array}{l}14775- \\
23640\end{array}$ & - \\
\hline 10 & 39 & $5 \times 4 \times 3.5$ & 16 & 910 & 13 & 0.05 & 65.00 & 1.31 & 12 & 6761 & 2230 \\
\hline 11 & - & - & 1507 & 361 & 0 & 1.42 & 0.53 & 1.31 & 103 & 676 & 13178 \\
\hline 12 & - & $2.7 \times 1.9$ & 11193 & 79726 & 0 & 0.38 & 3.13 & 1.31 & 260 & 2145 & 13734 \\
\hline
\end{tabular}

CA, catecholamine; A, adrenaline; NA, noradrenaline; DA, dopamine; - not examined; 0, not detected. 
Table 2 Concentrations of catecholamines in human pheochromocytoma and normal adrenal medulla tissue. Values are means \pm S.E of 12 samples.

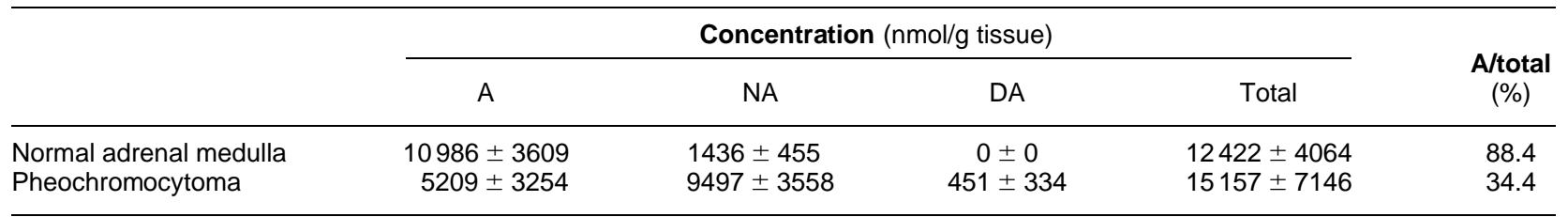

A, adrenaline; NA, noradrenaline; DA, dopamine.

Table 3 Concentrations of catecholamine-synthesizing enzymes mRNA and $\beta$-actin mRNA in pheochromocytomas and normal adrenal medullas. Values are means \pm S.E. for independent samples in experiments $A$ and $B$, expressed as ratios to the control value in normal adrenal medullas. The sample numbers are in parentheses.

\begin{tabular}{|c|c|c|c|c|c|}
\hline & TH & AADC & DBH & PNMT & $\beta$-actin \\
\hline \multicolumn{6}{|l|}{ Experiment $\mathrm{A}$} \\
\hline $\begin{array}{l}\text { Normal adrenal medulla (8) } \\
\text { Pheochromocytoma (4) }\end{array}$ & $\begin{array}{l}1.00 \pm 0.41 \\
2.43 \pm 0.94^{*} \dagger\end{array}$ & $\begin{array}{l}1.00 \pm 0.53 \\
5.65 \pm 0.49^{*}\end{array}$ & $\begin{array}{l}1.00 \pm 0.41 \\
5.32 \pm 3.34\end{array}$ & $\begin{array}{l}1.00 \pm 0.45 \\
0.16 \pm 0.06 \dagger\end{array}$ & $\begin{array}{l}1.00 \pm 0.16 \\
1.17 \pm 0.30\end{array}$ \\
\hline \multicolumn{6}{|l|}{ Experiment B } \\
\hline $\begin{array}{l}\text { Normal adrenal medulla (4) } \\
\text { Pheochromocytoma (8) }\end{array}$ & $\begin{array}{l}1.00 \pm 0.36 \\
5.96 \pm 1.19^{\star} \dagger\end{array}$ & & & $\begin{array}{l}1.00 \pm 0.48 \\
0.13 \pm 0.03^{*} \dagger\end{array}$ & $\begin{array}{l}1.00 \pm 0.18 \\
1.13 \pm 0.23\end{array}$ \\
\hline
\end{tabular}

$\mathrm{TH}$, tyrosine hydroxylase; AADC, aromatic L-amino acid decarboxylase; $\mathrm{DBH}$, dopamine $\beta$-hydroxylase; PNMT, phenylethanolamine $N$-methyl trasferase. ${ }^{*} P<0.05$ (Student's $t$-test); $\dagger P<0.05$ (Mann-Whitney U-test) compared with normal adrenal medulla.

no correlation between the tumor weight and the catecholamine content. Only the tissue adrenaline concentration correlated with the plasma and urinary adrenaline concentrations $(P<0.0001)$. The other tissue catecholamines did not correlate with the corresponding plasma and urinary catecholamines.

As shown in Table 2, the proportions of adrenaline, noradrenaline and dopamine found in the pheochromocytoma varied with the specimens, and 10 of the 12 pheochromocytomas contained more noradrenaline than adrenaline, whereas all 12 of the human normal adrenal medullas contained about $90 \%$ adrenaline. The mean content of total catecholamine in the pheochromocytomas was almost the same as that in the normal adrenal medullas.

The amounts of tyrosine hydroxylase, AADC and DBH mRNA in the pheochromocytomas were respectively $2.43,5.65$ and 5.32 times those in the normal adrenal medullas (Table 3, experiment A). This finding indicates that the gene expression of these catecholaminesynthesizing enzymes is increased in pheochromocytoma tissues. In contrast, the PNMT gene expression was about six to eight times greater in the normal adrenal medullas than in the pheochromocytoma tissues (Table 3). The levels of expression of the $\beta$-actin gene, a constitutive gene, were the same in the human adrenal medullas as in the pheochromocytomas (Table 3).

As the amount of catecholamines and the amount of the mRNAs varied among the pheochromocytoma tissue specimens (Table 2), we next examined the relationship between the TH gene expression and the tissue concentrations of catecholamines in the pheochromocytomas and normal adrenal medullas, because tyrosine hydroxylase is a rate-limiting enzyme of catecholamine biosynthesis. As shown in Fig. 1, the mRNA expressions correlated with the content of catecholamines in the tumors $(r=0.964, P<0.0001, n=12)$. In the normal adrenal medullas, the mRNA expressions were relatively lower compared with the high contents of catecholamines, and no correlation was observed $(r=0.421$, $P=0.2351, n=12)$.

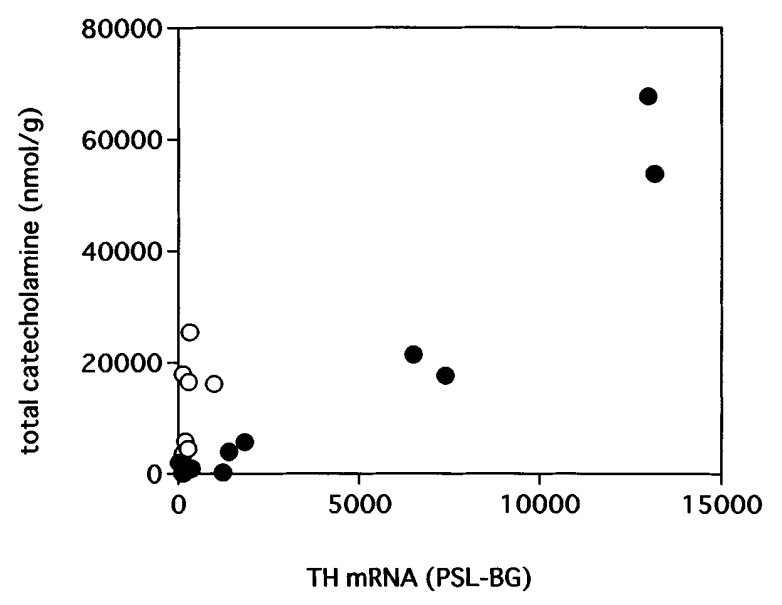

Figure 1 Correlation of tyrosine hydroxylase (TH) mRNA and total catecholamine concentrations in human pheochromocytomas $(\bullet)$ and normal adrenal medullas $(O)$ : radioactivities of tyrosine hydroxylase mRNAs (photostimulated luminescence minus background, PSL-BG) plotted against total catecholamines (nmol/g tissue) analyzed by HPLC. 


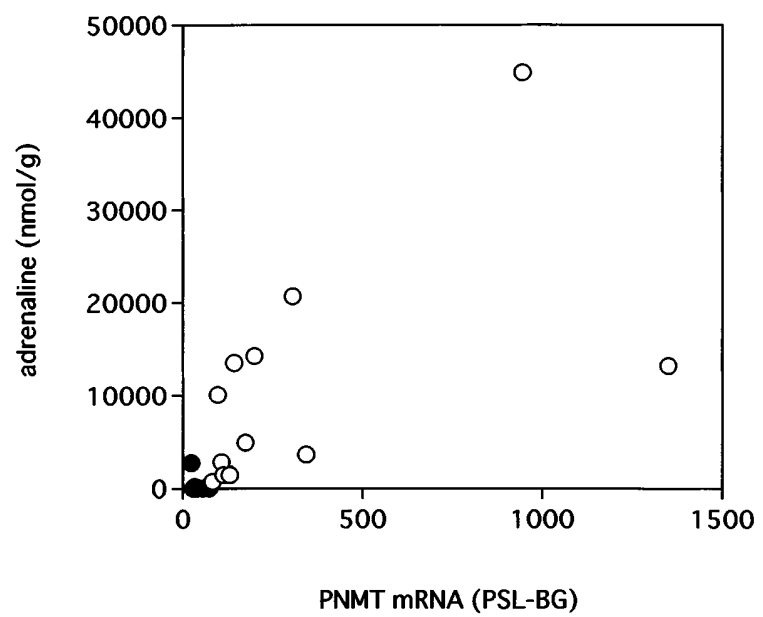

Figure 2 Correlation of phenylethanolamine $\mathrm{N}$-methyl transferase (PNMT) mRNA and adrenaline concentrations in human pheochromocytomas $(\bullet)$ and normal adrenal medullas $(O)$ : radioactivities of PNMT mRNAs (photostimulated luminescence minus background, PSL-BG) plotted against adrenaline (nmol/g tissue) analyzed by HPLC.

We then examined the relationship between the PNMT gene expression and adrenaline concentrations in the tissues. As shown in Fig. 2, both the mRNA expressions and adrenaline concentrations were lower in the tumors. In the normal adrenal medullas, the mRNA expressions were higher and correlated with the content of adrenaline $(r=0.574, P=0.05, n=12)$.

\section{Discussion}

Catecholamines are synthesized sequentially by four enzymes: tyrosine hydroxylase, AADC, DBH and PNMT. The results of this study indicated that the levels of expression of tyrosine hydroxylase, AADC and DBH mRNAs are greater in pheochromocytomas than in normal adrenal medullas, and PNMT mRNA concentrations are greater in normal adrenal medullas. These differences in mRNA expression are responsible for the difference in the proportions of catecholamines between pheochromocytomas and normal adrenal medullas.

There was a close correlation between the amounts of total catecholamine and the tyrosine hydroxylase mRNA concentrations in the tumors, but not in the normal adrenal medullas. Nakada et al. (19) reported that pheochromocytomas contained a significantly larger amount of catecholamines and greater tyrosine hydroxylase activity than did normal adrenal medullas. Iwase et al. (20) also observed high tyrosine hydroxylase activity in pheochromocytomas. Thus it is likely that tyrosine hydroxylase activity is mainly regulated by the tyrosine hydroxylase mRNA expression rather than by short-term control involving tyrosine hydroxylase protein phosphorylation in pheochromocytomas. The production of catecholamines in pheochromocytomas may be determined by the expression of the genes.
In contrast to the other genes, in the present study the level of expression of PNMT mRNA was found to be stronger in the normal adrenal medullas than in the pheochromocytomas. This might explain why sporadic pheochromocytomas usually predominantly produce noradrenaline. The high concentrations of PNMT mRNA in the normal adrenal medullas may have been induced by stimulation of glucocorticoid (21) release from the adrenal cortex, which surrounds the adrenal medullas. The low concentrations of PNMT mRNA in the pheochromocytomas might reflect an insufficient concentration of plasma cortisol in the artery supplying the tumor. Kimura et al. (22) also reported in an immunohistochemical study that tyrosine hydroxylase, AADC and $\mathrm{DBH}$ were detected in all functioning pheochromocytomas, and that PNMT was limited to the mixed-type pheochromocytomas that contain adrenaline and noradrenaline equally.

The expression of AADC and DBH mRNA was also enhanced in the present tumors. The mechanisms by which the expression of these genes is activated remain to be determined. Surgical stress may affect catecholamine secretion and synthesis, but probably did not affect the mRNAs concentrations in this study, because it takes several hours to increase the concentrations of mRNA. The high levels of expression may have relevance to the development or growth of pheochromocytomas. Second-messenger systems, especially protein kinase $\mathrm{C}$ and cAMP-dependent pathways, are known to affect the transcriptional regions of genes. The $5^{\prime}$ region of both the $\mathrm{TH}$ gene and the $\mathrm{DBH}$ gene contain a cAMP response element (CRE) that mediates transcriptional induction by cAMP. Other mechanisms, including growth factors, may regulate the expression of these genes. Goto et al. (23) suggested that pheochromocytomas are in a state of growth stimulation by growth factors, including insulin-like growth factor (IGF)-II and IGF-I/II receptors, and that c-fos and c-myc proto-oncogenes are expressed in this tumor. Further investigation to elucidate these mechanisms is necessary.

Thus we demonstrated that the gene expression of the catecholamine-synthesizing enzymes is increased in pheochromocytoma tissues and that there is a positive relationship between the levels of $\mathrm{TH}$ gene expression and the tissue concentrations of catecholamines in pheochromocytomas. The mechanism responsible for the expressions of these genes in pheochromocytomas remains to be investigated.

\section{Acknowledgements}

This study was supported in part by grant No. 06671000 from the Ministry of Education and by a grant from the University Research Project.

We are grateful for the generous assistance of Drs Yasushi Kawakami, Michiko Asano, Masato Odawara, Yukichi Okuda and Kamejirou Yamashita (Department 
of Internal Medicine), Tooru Yashiro (Department of Surgery) and Koji Kikuchi (Department of Urology) of Tsukuba University in obtaining tumors and thank Dr Shigeo Isaka, Chiba University for obtaining normal adrenal glands. We also thank Miss Sumiko Nissato for technical assistance.

\section{References}

1 Yanase T, Nawata H, Kato K \& Ibayashi H. Catecholamines and opioid peptides in human phaeochromocytomas. Acta Endocrinologica $1986113378-384$.

2 Yanase T, Nawata H, Kato K, Ibayashi H \& Matsuo H. Studies on adrenorphin in pheochromocytoma. Journal of Clinical Endocrinology and Metabolism $198764692-697$.

3 Isobe K, Yukimasa N, Takekoshi K, Nomura F \& Nakai T. Expression of mRNAs coding for catecholamine synthesizing enzymes in human adrenal pheochromocytoma. Japanese Journa of Clinical Pathology 199543 540-544.

4 Winkler H \& Smith AD. Pheochromocytoma and other catecholamine-producing tumors. In Catecholamines, ch 20, pp 900-933. Eds H Blaschko \& E Muscholl. Berlin: Springer Verlag, 1972.

5 Imashuku S, Takada H, Sawada T, Nakamura T \& Labrosse EH. Studies on tyrosine hydroxylase in neuroblastoma, in relation to urinary levels of catecholamine metabolites. Cancer 197536 450-457.

6 Haycock JW \& Wakade AR. Activation and multiple-site phosphorylation of tyrosine hydroxylase in perfused rat adrenal glands. Journal of Neurochemistry 199258 57-64.

7 Stachowiak MK, Jiang HK, Poisner AM, Tuominen RK \& Hong JS. Short and long term regulation of catecholamine biosynthetic enzymes by angiotensin in cultured adrenal medullary cells Journal of Biological Chemistry 1990265 4694-4702.

8 Isobe K, Yukimasa N, Nakai T \& Takuwa Y. Pituitary adenylate cyclase-activating polypeptide induces gene expression of the catecholamine synthesizing enzymes, tyrosine hydroxylase and dopamine $\beta$-hydroxylase, through $3^{\prime}, 5^{\prime}$-cyclic adenosine monophosphate- and protein kinase C-dependent mechanisms in cultured porcine adrenal medullary chromaffin cells. Neuropeptides $199630167-175$.

9 Sheng M, McFadden G \& Greenberg ME. Membrane depolarization and calcium induces c-fos transcription via phosphorylation of transcription factor CREB. Neuron 19904 571-582.

10 Fossom LH, Carlson CD \& Tank W. Stimulation of tyrosine hydroxylase gene transcription rate by nicotine in rat adrenal medulla. Molecular Pharmacology 199140 193-202.

11 Gizang-Ginsberg E \& Ziff EB. Nerve growth factor regulates tyrosine hydroxylase gene transcription through a nucleoprotein complex that contain c-Fos. Genes and Development 199044177 4191 .
12 Hiremagalur B, Nankova B, Nitahara J, Zeman R \& Sabban EL. Nicotine increases expression of tyrosine hydroxylase gene. Journal of Biological Chemistry 1993268 23704-23711.

13 Czyzyk-Krzeska MF, Furnari BA, Lawson EE \& Millhorn DE. Hypoxia increases rate of transcription and stability of tyrosine hydroxylase mRNA in pheochromocytoma (PC12) cells. Journal of Biological Chemistry 1994269 760-764.

14 Tumer N, Brown JW, Carballeira A \& Fishman LM. Tyrosine hydroxylase gene expression in varying forms of human pheochromocytoma. Life Sciences 199659 1659-1665.

15 Kaneda N, Kobayashi K, Ichinose H, Kishi F, Nakazawa A, Kurosawa $\mathrm{Y}$ et al. Isolation of a novel cDNA clone for human tyrosine hydroxylase: alternative RNA splicing produces four kinds of mRNA from a single gene. Biochemical and Biophysical Research Communications 1989146 971-975.

16 Kobayashi K, Kurosawa Y, Keisuke F \& Nagatsu T. Human dopamine beta-hydroxylase gene: two mRNA types having different 3-terminal regions are produced through alternative polyadenylation. Nucleic Acids Research 198917 1089-1102.

17 Ichinose H, Kurosawa Y, Titani K, Fujita K \& Nagatsu T. Isolation and characterization of a cDNA clone encoding human aromatic l-amino acid decarboxylase. Biochemical and Biophysical Research Communications 1989164 1024-1030.

18 Kaneda N, Ichinose H, Kobayashi K, Oka K, Kishi F, Nakazawa A et al. Molecular cloning of cDNA and chromosomal assignment of the gene for human phenylethanolamine $N$-methyltransferase, the enzyme for epinephrine biosynthesis. Journal of Biological Chemistry $19882637672-7677$.

19 Nakada T, Furuta H \& Katayama T. Catecholamine metabolism in pheochromocytoma and normal adrenal medullae. Journal of Urology $19881401348-1351$.

20 Iwase K, Nagasaka A, Nagatsu I, Kikuchi K, Nagatsu T, Funahashi $\mathrm{H}$ et al. Tyrosine hydroxylase induces cell differentiation of catecholamine biosynthesis in neuroendocrine tumors. Journal of Endocrinological Investigation 199417 235-239.

21 Betito K, Diorio J, Meaney MJ \& Bosksa P. Adrenal phenylethanolamine $N$-methyltransferase induction in relation to glucocorticoids receptor dynamics: evidence that acute exposure to high cortisol levels is sufficient to induce the enzyme. Journal of Neurochemistry 199258 1853-1862.

22 Kimura N, Miura Y, Nagatsu I \& Nagura H. Catecholamine synthesizing enzymes in 70 cases of functioning and nonfunctioning phaeochromocytoma and extra-adrenal paraganglioma. Virchows Archiv A, Pathological Anatomy and Histopathology $199242125-32$.

23 Goto K, Ogo A, Yanase T, Haji M \& Nawata H. Expression of c-fos and c-myc protooncogenes in human adrenal pheochromocytoma. Journal of Laboratory and Clinical Medicine 1990115 449-453.

Received 6 January 1997

Accepted 25 August 1997 